\title{
Ischemia/Reperfusion Injury and its Consequences on Immunity and Inflammation
}

\author{
Bendix R. Slegtenhorst • Frank J. M. F. Dor • \\ Hector Rodriguez • Floris J. Voskuil • Stefan G. Tullius
}

Published online: 31 May 2014

(C) Springer International Publishing AG 2014

\begin{abstract}
Ischemia/reperfusion injury (IRI), an inherent component of transplantation, affects organ quality and transplant outcomes. Although the complexity of the pathophysiology is recognized, detailed mechanisms remain unclear, and strategies preventing the consequences of IRI have been challenging. Of critical significance appears to be the link between IRI, the initiation of innate immune responses, and the (potential) augmentation of adaptive immunity. An improved understanding of those complex mechanisms and interactions may pave the way for more effective treatment strategies.
\end{abstract}

Keywords Ischemia-reperfusion injury · Innate immunity · Inflammation

\section{Introduction}

Innate immune responses are a critical component of organ transplantation affecting both immediate organ function and long-term graft survival. Mechanisms linking innate and

B. R. Slegtenhorst • H. Rodriguez · F. J. Voskuil • S. G. Tullius $(\bowtie)$ Division of Transplant Surgery and Transplant Surgery Research Laboratory, Department of Surgery, Brigham and Women's Hospital, Harvard Medical School, 75 Francis Street, Boston, MA 02115, USA e-mail: stullius@partners.org

B. R. Slegtenhorst • F. J. M. F. Dor

Division of Transplant Surgery, Department of Surgery, Erasmus MC-University Medical Center, Rotterdam, The Netherlands

H. Rodriguez

Department of Cardiovascular Surgery, University Hospital of

Zurich, Zurich, Switzerland

F. J. Voskuil

Division of Nephrology, Renal Transplant Unit, Department of Medicine, University Medical Center Groningen, Groningen, The Netherlands adaptive immunity are poorly understood and insufficiently addressed in current established treatment approaches.

The concept of an 'injury response' as a link between injury, immune responses, and transplant outcomes has been proposed several years ago [1] based on the notion that immune cells become activated by danger/alarm signals from injured cells rather than solely through the recognition of 'non-self' [2]. While the impact of innate immunity on transplant outcome is recognized, key players, mechanisms, and potential treatment targets require a more in-depth analysis.

Here, we provide an overview of mechanistic events subsequent to ischemia/reperfusion injury (IRI) with a focus on key components of a complex interplay between innate and adaptive immunity in addition to current experimental and clinical treatment concepts.

\section{Ischemic Injury}

Interruption of blood supply is inevitable following procurement of an organ for transplantation. Deprivation of oxygen and nutrients trigger a series of events that lead to cell injury and death. As oxygen levels fall, there is a transition from aerobic to an anaerobic metabolism, resulting in the accumulation of metabolic byproducts and cellular acidification. Metabolic demand eventually exceeds compensatory adenosine triphosphate (ATP) production, and ATP levels fall to critically low levels. Consequently, ATP-dependent membrane pumps fail, leading to an accumulation of intracellular sodium and calcium, followed by cell swelling, membrane rupture, and ultimately oncotic cell death.

Limiting ischemic times by restoring perfusion and supplying oxygen and nutrients is therefore a vital aspect of reducing ischemia-related injury. Reperfusion by itself, however, triggers a new series of detrimental cellular processes that exacerbate injury and cell death (Fig. 1). 


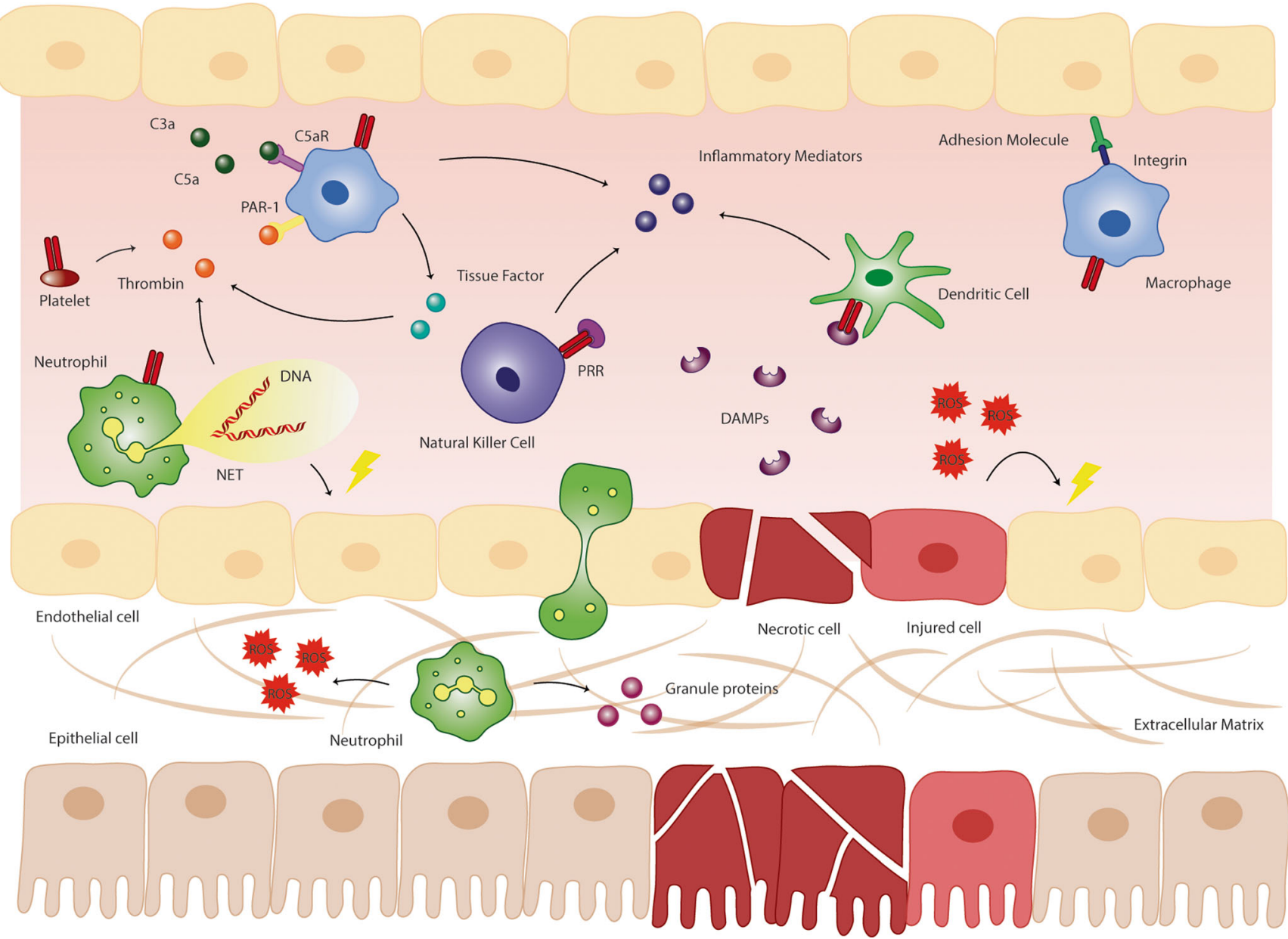

Fig. 1 Damage-associated molecular patterns (DAMPs), released from necrotic and injured cells, activate pattern recognition receptors (PRRs) expressed on innate immune cells and epithelial and endothelial cells. Consequently, inflammatory cytokines and chemokines are produced. Injured cells produce reactive oxygen species (ROS) that are cytotoxic. Activated endothelial cells upregulate expression of adhesion molecules, thereby facilitating leukocyte adhesion and transmigration. Neutrophils release neutrophil extracellular traps (NETs) that are both pro-thrombotic

\section{Reperfusion Injury}

Reperfusion subsequent to ischemia generates reactive oxygen species (ROS), mitochondrial failure, endothelial dysfunction, and sterile inflammation. Under physiological conditions, mitochondria generate small quantities of ROS through the leakage of electrons. When exposed to ischemia, however, mitochondrial complexes are damaged, resulting in an excessive generation of ROS beyond antioxidantscavenging capacity upon reperfusion [3]. ROS, in turn, cause damage to membrane lipids, proteins, and nucleic acids that can lead to cell death [4]. Additionally, the mitochondrial permeability transition pore (mPTP), a non-specific pore formed in the inner mitochondrial membrane allowing entry of molecules $<1.5 \mathrm{kDa}$, is activated subsequent to exposure to ROS and increased mitochondrial calcium levels. This and cytotoxic. Neutrophils also engage in the respiratory burst and release their granule proteins. Macrophages and neutrophils release microvesicles containing thrombin and platelets express PRRs that mediate the generation of thrombin. Thrombin activates innate immune cells through proteinase-activated receptor 1 (PAR-1) ligation resulting in the production of inflammatory cytokines and chemokines. The complement system is activated, providing a chemotactic gradient as well as an activating cue for innate immune cells through their cognate receptors

phenomenon results in a disruption of the electrochemical gradient, uncoupling of oxidative phosphorylation, and ATP depletion. Moreover, an augmented osmotic pressure is linked to mitochondrial swelling and membrane rupture, resulting in necrosis or apoptosis [5]. Finally, ROS contributes to a proinflammatory environment by promoting the formation of the NLRP3 inflammasome [6], a multiprotein complex that, in turn, activates caspase- 1 . Subsequently, caspase- 1 cleaves the precursor pro-interleukin (IL)-1 $\beta$, forming the proinflammatory cytokine IL-1 $\beta$ [7].

The graft microvasculature is particularly sensitive to IRI [8]. Subsequent to reperfusion, blood flow to ischemic tissue is not immediately restored completely. This process, termed the 'no-reflow phenomenon', is thought to be linked to endothelial cell swelling and intravascular plugging by leukocytes, fibrin, or platelets, all contributing to intravascular obstruction 
[9]. In the context of IRI, damaged and activated endothelial cells also lose barrier function, becoming more permeable and allowing the transmigration of leukocytes. Moreover, endothelial cells are sensitive to biomechanical forces generated by blood flow. Flow-mediated shear stress induces the vasoprotective transcription factor KLF2, which suppresses the IL-1 $\beta$-mediated endothelial induction of E-selectin and vascular cell adhesion molecule 1 (VCAM-1) [10]. Cessation of blood flow in the context of organ preservation has been shown to trigger endothelial dysfunction mediated by a decay of KLF2 [11]. Interruption of blood flow therefore primes the endothelium for activation by pro-inflammatory cytokines and, once activated, the endothelium promotes leukocyte adhesion and transmigration.

After restoring perfusion, a sterile inflammatory response is induced through the release of endogenous molecules from necrotic and injured cells. Inflammation is an important process required for tissue repair and regeneration through the clearance of dead cells and the release of growth factors and chemokines that induce cell proliferation and angiogenesis. However, the release of ROS, proteases, and fibrosispromoting factors, all aspects of inflammation, are detrimental. In IRI, inflammation becomes excessive and injury and repair become unbalanced, with innate immune cells playing a critical role in mediating injury responses.

\section{Innate Immune Responses Subsequent to Ischemia/Reperfusion Injury}

The innate immune system is an evolutionary conserved first line of defense, capable of acting rapidly upon infection through recognition of repeating structures expressed by microbes, termed pathogen-associated molecular patterns (PAMPs) that are recognized by pattern recognition receptors (PRRs) [12]. All cells of the innate immune system, including neutrophils, monocytes, macrophages, dendritic cells (DC), and natural killer (NK) cells express PRRs and therefore contribute to a pro-inflammatory environment that is established following reperfusion. Additionally, non-immune cells such as endothelial [13] and epithelial cells [14] express PRRs. This heterogeneous group of receptors includes Tolllike receptors (TLRs), NOD-like receptors (NLRs), C-type lectin receptors (CLRs), and RIG-I-like receptors (RLRs) located on cellular membranes, intracellularly, or secreted in soluble form. PRRs also respond to endogenous molecules, so-called danger-associated molecular patterns (DAMPs), that are released by injured and necrotic cells in response to IRI. DAMPs include high mobility group box-1 (HMGB1), heparan sulfate, ATP, nuclear DNA, mitochondrial DNA, and RNA [15]. Ligation of PRRs results into the activation of the inflammasome [16] in addition to the induction of nuclear factor- $\mathrm{KB}(\mathrm{NF}-\mathrm{KB})$ and mitogen-activated protein kinases
(MAPK) pathways. As a result, pro-inflammatory cytokines and chemokines, including IL-1, IL-6, tumor necrosis factor- $\alpha$ (TNF- $\alpha$ ), monocyte chemoattractant protein 1 (MCP-1), and IL-8 are induced $[15,17]$ and major histocompatibility complex (MHC) and co-stimulatory molecules are upregulated [18]. Interestingly, oxidative stress has been reported to upregulate TLRs in macrophages [19], augmenting the inflammatory response. Experimental knockout (KO) models have shown that TLR4- [20] and TLR2-deficient mice [21] are protected from IRI while exposure to an administered TLR agonist augments acute rejection of cardiac allografts [22]. Thus, at least in theory, IRI forms an important link between innate and adaptive immunity. Indeed, alloimmunity was enhanced through the activation of the innate immune system subsequent to TLR ligation in experimental transplant models [23-26]. Although all cells of the innate immune system are capable of sensing DAMPs, specific cells have been shown to play distinct roles.

\section{Neutrophils}

Neutrophils are the largest circulating fraction of leukocytes and first to arrive at the site of injury [27]. Their involvement in transplantation has been shown in experimental models, in which the inhibition of neutrophil chemotaxis prolonged allograft survival [28]. Neutrophils are recruited by signals provided by chemokines that are produced by tissue-resident macrophages and endothelial cells [29]. Rolling adhesion and then tight adhesion are initiated through the upregulation of adhesion molecules on endothelial cells. Once neutrophils transmigrate through the endothelium, they release the content of their granules containing proteases and then engage in a process termed the 'respiratory burst' involving the release of ROS. Additional leukocytes are recruited through the production of cytokines and chemokines by neutrophils. Moreover, neutrophils have the capacity to produce neutrophil extracellular traps (NETs) by releasing nuclear chromatin and granule proteins [30]. NETs primarily capture and kill microbes during infection but have recently also been shown to be involved in cardiac IRI. Indeed, KO mice incapable of producing NETs were protected from the consequences of ischemia [31]. Similarly, decreased NET levels in TLR4 KO mice ameliorated damages subsequent to hind-limb IRI [32].

\section{Mononuclear Phagocytes}

Mononuclear phagocytes comprise a group of myeloidderived monocytes, macrophages, and DCs [33]. Circulating monocytes are recruited through chemotaxis. Upon arrival at the injury site, they differentiate into tissue macrophages or DCs. Macrophages demonstrate a high degree of plasticity and assume a pro-inflammatory or anti-inflammatory phenotype depending on micro-environmental cues [34]. Similar to 
the T-helper (Th)1/Th2 polarization framework established in $\mathrm{T}$ cells, macrophages can undergo M1 and M2 polarization. TLR ligation and stimulation with interferon (IFN)- $\gamma$ promote M1 activation, whereas IL-10, IL-4, and IL-13 promote M2 skewing [35]. After exposure to the inflammatory environment subsequent to IRI, macrophages assume a M1 polarization and promote inflammation through cytokine production. Depletion of macrophages prior to IRI has been shown to ameliorate injury in an experimental murine kidney IRI model. In contrast, when macrophages were depleted days after injury, impaired tubular proliferation and repair were observed linked to the depletion of M2 macrophages [36•].

DCs form a critical link between innate and adaptive immunity. Once activated, they orchestrate the adaptive immune response through maturation and migration to lymphoid tissues [37]. DCs that originate from donor organ tissue or circulating recipient DCs have the capacity to activate PRRs following IRI $[38,39]$. However, DCs are also capable of modulating peripheral $\mathrm{T}$ cell tolerance [40] and may play a protective role in IRI [41]. It has been proposed that donor resident DCs, but not circulating DCs, are protective during hepatic IRI [42]. In a murine kidney IRI and transplant model, loss of donor tissue resident DCs has been linked to progressive T cell recruitment [43]. These data demonstrate dual roles for DCs in IRI, presumably depending on location and microenviromental cues.

\section{Natural Killer Cells}

Natural killer cells are cytotoxic lymphocytes that are capable of distinguishing between self and non-self by activating and inhibiting surface receptors [44]. MHC-1 expression forms an inhibitory signal for NK cells while downregulation of MHC1 enables NK cell activation and cytolysis, a paradigm known as the missing-self hypothesis [45]. In transplantation, allogeneic cells lack recipient MHC-1 alleles, leading to NK cell activation and a more rapid rejection [46]. However, others have reported on a tolerance-promoting role for NK cells by targeting donor antigen-presenting cells (APCs) [47]. The role of NK cells specific to IRI has not been well-characterized. NK cells were shown to be recruited through tubular epithelial cell (TEC) production of the chemokine CCR5 following TLR2 ligation by DAMPs in a renal IRI model [48]. Subsequently, NK cells contribute to IRI through upregulation of CD137L, stimulating additional chemokine production by epithelial cells and recruitment of neutrophils [49]. IL-17 production by NK cells has been implicated as an immuneactivating mechanism in a hepatic IRI model [50]. Moreover, NK cells have also been reported to directly target signaling stressed epithelial cells by inducing apoptosis. In a renal IRI model, expression of reninoic acid early inducible (Rae-1) was upregulated following IRI, thereby providing a signal activating the NK cell receptor NK group 2 member D (NKG2D) that induces apoptotic cell death [51].

\section{Activating the Complement Cascade}

The complement system can be initiated by three pathways: the classical, alternative, and lectin pathways. These pathways are composed of circulating precursor proteins that can be enzymatically activated. While the activation of different pathways is distinct, they converge with the activation of $\mathrm{C} 3$ convertase, leading to the formation of the membrane attack complex (MAC), which is capable of forming a lytic pore into the pathogen's cell wall [52]. Other functions of activated complement components include chemotaxis and opsonization [53]. All three pathways are thought to be activated in IRI [54]. Lysis of parenchymal cells by the MAC [52], C3a- and C5a-induced recruitment of leukocytes through chemotaxis, and production of inflammatory cytokines and chemokines [55] have been implicated as injury-mediating mechanisms in IRI. The critical role of the lectin activation pathway by mannose binding lectin (MBL) in renal IRI has been demonstrated in several experimental studies [56-58]. Absence of MBL was shown to be protective against the adverse effects of renal IRI with significantly less tissue damage, while reconstitution of MBL aggravated injury. Emerging evidence indicates that conventional routes of the lectin pathway may be bypassed in IRI. In a cardiac IRI model, inhibition of complement activation through the lectin pathway was shown to reduce tissue injury independent of $\mathrm{C} 4$ activation [59]. Moreover, therapeutic inhibition of MBL by a monoclonal antibody against MBL-A (P7E4) was protective against renal IRI in a rat model. Interestingly, the MBLmediated tubular injury was shown to be completely independent of complement activation as interference with $\mathrm{C} 3$ or $\mathrm{C} 5$ was not protective against renal IRI, suggesting a direct cytotoxic effect of MBL [60].

\section{Coagulation and Platelet Activation}

Historically, coagulation, platelet activation, and hemostasis have been viewed as being separated from immune responses. Recent work, however, has suggested that innate immunity and thrombosis act in concert in a process that has been coined immunothrombosis [61]. In this conceptual framework, innate immune cells induce thrombosis while platelets and coagulation pathways activate immune responses. A number of findings support this hypothesis and also provide a link to IRI. Monocytes and neutrophils are known to contain microvesicles with tissue factor (TF) [62•]. When activated, these microvesicles are released and promote coagulation through the extrinsic pathway, while NETs induce coagulation through the intrinsic pathway [61]. Protease-activated receptors (PARs), expressed on all cells of the innate immune 
system, in turn, are activated by coagulation proteases such as thrombin leading to induction of pro-inflammatory cytokines [63]. Moreover, platelets release thrombin in response to DNA released by necrotic cells, mediated through TLR2 and TLR4 ligation [64]. Serotonin release from platelets promotes recruitment of neutrophils [65]. Experimental data indicate that these processes may also play a role in IRI. In a renal IRI model, inhibition of TF ameliorated kidney injury [66], possibly through the reduction of microthrombus formation. PAR-1 deficiency protected against renal IRI [67] and treatment with activated protein $\mathrm{C}$ protected from cardiac IRI through inhibition of PAR-1 [68].

\section{Clinical Implications and Novel Therapies}

Improvement of organ preservation and allocation are both effective strategies to limit IRI. It is well-established that cold ischemic times (CIT) are an important determining factor for the degree of organ injury and thus transplant outcomes. In a retrospective study in kidney transplantation patients, DGF was clearly linked to prolonged ischemia [69]. Moreover, rates of acute rejection were not only linked to prolonged ischemia [70], but CIT exceeding $18 \mathrm{~h}$ was associated with a decreased graft survival [71]. Marginal, nowadays mostly called extended criteria donor (ECD), organs seem particularly sensitive to prolonged ischemia [72]. Moreover, when CIT had been minimized, outcomes of ECD and standard criteria donor (SCD) transplantations were comparable [73•]. The Eurotransplant Senior Program was established with the aim of allocating older kidneys with minimal ischemia times to older recipients, termed by some as the 'Old for Old' program. Of note, outcomes of older organs transplanted within this program were comparable with those of younger organs [74]. Optimizing allocation schemes and reducing CIT is therefore a strategy that remains relevant, particularly in times when utilization of ECD organs continues to increase.

In most transplant centers, cold static preservation is currently the standard method of organ preservation. However, clinical trials on machine perfusion have recently shown superiority $[75,76]$. The benefits of machine perfusion involve the ability to supply nutrients and oxygen to the organ while washing out metabolic and toxic waste products [77]. In addition, maintaining a protective vascular phenotype mediated by the flow-responsive endothelium may be a mechanism by which machine pulsatile perfusion provides protection [11, 78]. Preclinical and clinical trials are currently in the process of evaluating outcomes for extrarenal organs.

Ex vivo conditioning of the donor organ could provide another avenue of interest. Currently, the EMPIRIKAL [An Investigation into the Efficacy of Mirococept for Preventing Ischaemia-Reperfusion Injury in the Kidney ALlograft] trial is assessing the efficacy of donor kidney treatment with the complement inhibitor Mirococept (APT070) for the prevention of IRI (ISRCTN49958194). Mirococept is a membrane-localizing complement regulatory protein derived from human complement receptor type 1 (CR1) that inhibits $\mathrm{C} 3$ and $\mathrm{C} 5$ convertases of both the classical and alternative pathways. Moreover, Mirococept has been identified as a cofactor for the degradation of $\mathrm{C} 3 \mathrm{~b}$ and $\mathrm{C} 4 \mathrm{~b}$. In experimental models, donor treatment with Mirococept was linked to enhanced graft function and survival [79]. Ex vivo tacrolimus treatment of marginal liver grafts is currently being evaluated clinically in the TOP (Tacrolimus Organ Perfusion) study (NCT01564095). Prior to implantation, livers are rinsed with $1,000 \mathrm{~mL}$ rinse solution containing $20 \mathrm{ng} / \mathrm{mL}$ of tacrolimus. In an experimental liver transplant model, ex vivo treatment with tacrolimus ameliorated IRI possibly through preservation of glutathione homeostasis [80].

Ischemic conditioning is based on inducing a protected state in the donor organ by delivering short periods of ischemia either before (pre-conditioning) [81] or after (postconditioning) [82] the onset of ischemia. The beneficial effects may also be achieved by using remote conditioning, in which the conditioning stimulus is submitted by inducing periods of ischemia at a remote area such as the upper or lower extremities [83]. The mechanisms of action are not completely understood, but are thought to include preservation of mitochondrial function and inhibition of ROS generation, upregulation of antioxidants, production of protective heat shock proteins, and inhibition of apoptosis [84]. Remote ischemic preconditioning is currently being evaluated in kidney transplantation using a blood pressure cuff on the arms of both donor and recipients $24 \mathrm{~h}$ prior to transplantation [REPAIR (Renal Protection Against Ischaemia-Reperfusion in Transplantation) trial; ISRCTN30083294] and on the leg of the recipient right before reperfusion of the kidney (Context trial; NCT01395719).

Current immunosuppressive treatments in transplantation target the adaptive immune system while innate immune responses are getting increasingly recognized as a potential target for immunosuppression. Experimental TLR inhibition has been proven to be effective in ameliorating IRI. A phase I trial was recently published evaluating the safety of a monoclonal antibody against TLR2 [85]. A follow-up phase II trial is currently in progress in renal transplant patients at high risk of delayed graft function (NCT01794663). Another phase I study is currently determining safety, tolerability, and distribution of a monoclonal antibody against TLR4 (NCT01808469). Tolerogenic and immunomodulating capacities of innate immune cells can potentially be exploited with cell-based therapies. A pilot study evaluated the effect of administrating regulatory macrophages ( $\mathrm{M}$ regs) to two living-donor renal transplant recipients [86]. While adverse effects were absent, patients could be kept on a low-dose 
maintenance immunosuppressive regimen. The ONE Study has been established with the aim to test several cell based therapies, including administration of $\mathrm{M}$ regs and tolerogenic DCs in kidney transplant recipients [87].

\section{Conclusion}

IRI affects all organs utilized for transplantation. Accumulating evidence suggests that organ injury is linked to allo-immune-independent and -dependent immune responses in a complex interplay of innate and adaptive immunity. Pulsatile machine perfusion, ischemic conditioning, and ex vivo pharmacological conditioning are promising optimizations that can limit IRI. Furthermore, directly targeting innate immune responses and exploiting tolerogenic innate immune properties could supplement current immunosuppressive treatments that focus largely on adaptive immunity. These treatment modalities have already shown encouraging results in experimental models and are currently being evaluated clinically. As we are just beginning to comprehend the complex interactions of injury and immune responses in the context of transplantation, developing a more thorough mechanistic understanding may lead to more efficacious future therapies that will ultimately improve transplant outcomes.

Acknowledgments Supported by grants from the National Institutes of Health (RO1AG039449) and the Carlos Slim Foundation de la Salud (all to SGT), and The Dutch Kidney Foundation (to BRS).

\section{Compliance with Ethics Guidelines}

Conflict of Interest Bendix R. Slegtenhorst, Frank J.M.F. Dor, Hector Rodriguez, Floris J. Voskuil, and Stefan G. Tullius declare that they have no conflict of interest.

Human and Animal Rights and Informed Consent This article does not contain any studies with human or animal subjects performed by any of the authors.

\section{References}

Papers of particular interest, published recently, have been highlighted as:

- Of importance

1. Land W, Schneeberger H, Schleibner S, Illner WD, Abendroth D, Rutili G, et al. The beneficial effect of human recombinant superoxide dismutase on acute and chronic rejection events in recipients of cadaveric renal transplants. Transplantation. 1994;57(2):211-7.
2. Matzinger P. Tolerance, danger, and the extended family. Annu Rev Immunol. 1994;12:991-1045.

3. Chen Q, Moghaddas S, Hoppel CL, Lesnefsky EJ. Ischemic defects in the electron transport chain increase the production of reactive oxygen species from isolated rat heart mitochondria. Am J Physiol Cell Physiol. 2008;294(2):C460-6.

4. Jaeschke H, Woolbright BL. Current strategies to minimize hepatic ischemia-reperfusion injury by targeting reactive oxygen species. Transplant Rev (Orlando). 2012;26(2):103-14.

5. Halestrap AP. What is the mitochondrial permeability transition pore? J Mol Cell Cardiol. 2009;46(6):821-31.

6. Gross O, Thomas CJ, Guarda G, Tschopp J. The inflammasome: an integrated view. Immunol Rev. 2011;243(1):136-51.

7. Tschopp J, Schroder K. NLRP3 inflammasome activation: the convergence of multiple signalling pathways on ROS production? Nat Rev Immunol. 2010;10(3):210-5.

8. Tuuminen R, Syrjala S, Krebs R, Keranen MA, Koli K, AboRamadan U, et al. Donor simvastatin treatment abolishes rat cardiac allograft ischemia/reperfusion injury and chronic rejection through microvascular protection. Circulation. 2011;124(10):1138-50.

9. Rezkalla SH, Kloner RA. No-reflow phenomenon. Circulation. 2002;105(5):656-62.

10. Parmar KM, Larman HB, Dai G, Zhang Y, Wang ET, Moorthy SN, et al. Integration of flow-dependent endothelial phenotypes by kruppel-like factor 2. J Clin Invest. 2006;116(1):49-58.

11. Gracia-Sancho J, Villarreal Jr G, Zhang Y, Yu JX, Liu Y, Tullius SG, et al. Flow cessation triggers endothelial dysfunction during organ cold storage conditions: strategies for pharmacologic intervention. Transplantation. 2010;90(2):142-9.

12. Takeuchi O, Akira S. Pattern recognition receptors and inflammation. Cell. 2010;140(6):805-20.

13. Opitz B, Hippenstiel S, Eitel J, Suttorp N. Extra- and intracellular innate immune recognition in endothelial cells. Thromb Haemost. 2007;98(2):319-26.

14. Nace GW, Huang H, Klune JR, Eid RE, Rosborough BR, Korff S, et al. Cellular-specific role of toll-like receptor 4 in hepatic ischemia-reperfusion injury in mice. Hepatology. 2013;58(1):374 87.

15. Chen GY, Nunez G. Sterile inflammation: sensing and reacting to damage. Nat Rev Immunol. 2010;10(12):826-37.

16. Ogura Y, Sutterwala FS, Flavell RA. The inflammasome: first line of the immune response to cell stress. Cell. 2006;126(4):659-62.

17. Frangogiannis NG. Chemokines in ischemia and reperfusion. Thromb Haemost. 2007;97(5):738-47.

18. Mills KH. TLR-dependent T, cell activation in autoimmunity. Nat Rev Immunol. 2011;11(12):807-22.

19. Powers KA, Szaszi K, Khadaroo RG, Tawadros PS, Marshall JC, Kapus A, et al. Oxidative stress generated by hemorrhagic shock recruits toll-like receptor 4 to the plasma membrane in macrophages. J Exp Med. 2006;203(8):1951-61.

20. Wu H, Chen G, Wyburn KR, Yin J, Bertolino P, Eris JM, et al. TLR4 activation mediates kidney ischemia/reperfusion injury. J Clin Invest. 2007;117(10):2847-59.

21. Farrar CA, Keogh B, McCormack W, O'Shaughnessy A, Parker A, Reilly $\mathrm{M}$, et al. Inhibition of TLR2 promotes graft function in a murine model of renal transplant ischemia-reperfusion injury. FASEB J. 2012;26(2):799-807.

22. Chen L, Wang T, Zhou P, Ma L, Yin D, Shen J, et al. TLR engagement prevents transplantation tolerance. Am J Transplant. 2006;6(10):2282-91.

23. Huang Y, Yin H, Han J, Huang B, Xu J, Zheng F, et al. Extracellular hmgb1 functions as an innate immune-mediator implicated in murine cardiac allograft acute rejection. Am J Transplant. 2007;7(4): 799-808.

24. Moser B, Szabolcs MJ, Ankersmit HJ, Lu Y, Qu W, Weinberg A, et al. Blockade of RAGE suppresses alloimmune reactions in vitro 
and delays allograft rejection in murine heart transplantation. Am J Transplant. 2007;7(2):293-302.

25. Shen H, Song Y, Colangelo CM, Wu T, Bruce C, Scabia G, et al. Haptoglobin activates innate immunity to enhance acute transplant rejection in mice. J Clin Invest. 2012;122(1):383-7.

26. Tesar BM, Jiang D, Liang J, Palmer SM, Noble PW, Goldstein DR. The role of hyaluronan degradation products as innate alloimmune agonists. Am J Transplant. 2006;6(11):2622-35.

27. Nathan C. Neutrophils and immunity: challenges and opportunities. Nat Rev Immunol. 2006;6(3):173-82.

28. El-Sawy T, Belperio JA, Strieter RM, Remick DG, Fairchild RL. Inhibition of polymorphonuclear leukocyte-mediated graft damage synergizes with short-term costimulatory blockade to prevent cardiac allograft rejection. Circulation. 2005;112(3):320-31.

29. Phillipson M, Kubes P. The neutrophil in vascular inflammation. Nat Med. 2011;17(11):1381-90.

30. Brinkmann V, Reichard U, Goosmann C, Fauler B, Uhlemann Y, Weiss DS, et al. Neutrophil extracellular traps kill bacteria. Science. 2004;303(5663):1532-5.

31. Savchenko AS, Borissoff JI, Martinod K, De Meyer SF, Gallant M, Erpenbeck L, et al. VWF-mediated leukocyte recruitment with chromatin decondensation by PAD4 increases myocardial ischemia/reperfusion injury in mice. Blood. 2014;123(1):141-8.

32. Oklu R, Albadawi H, Jones JE, Yoo HJ, Watkins MT. Reduced hind limb ischemia-reperfusion injury in toll-like receptor-4 mutant mice is associated with decreased neutrophil extracellular traps. J Vasc Surg. 2013;58(6):1627-36.

33. Geissmann F, Manz MG, Jung S, Sieweke MH, Merad M, Ley K. Development of monocytes, macrophages, and dendritic cells. Science. 2010;327(5966):656-61.

34. Gordon S, Martinez FO. Alternative activation of macrophages: mechanism and functions. Immunity. 2010;32(5):593-604.

35. Locati M, Mantovani A, Sica A. Macrophage activation and polarization as an adaptive component of innate immunity. Adv Immunol. 2013;120:163-84.

36. Lee S, Huen S, Nishio H, Nishio S, Lee HK, Choi BS, et al. Distinct macrophage phenotypes contribute to kidney injury and repair. J Am Soc Nephrol. 2011;22(2):317-26. This study demonstrates the dual role of macrophages in ischemia-reperfusion injury, depending on their polarization state.

37. Manfredi AA, Capobianco A, Esposito A, De Cobelli F, Canu T, Monno A, et al. Maturing dendritic cells depend on RAGE for in vivo homing to lymph nodes. J Immunol. 2008;180(4):2270-5.

38. Tsung A, Zheng N, Jeyabalan G, Izuishi K, Klune JR, Geller DA, et al. Increasing numbers of hepatic dendritic cells promote HMGB1-mediated ischemia-reperfusion injury. J Leukoc Biol. 2007;81(1):119-28.

39. Kim BS, Lim SW, Li C, Kim JS, Sun BK, Ahn KO, et al. Ischemiareperfusion injury activates innate immunity in rat kidneys. Transplantation. 2005;79(10):1370-7.

40. Morelli AE, Thomson AW. Tolerogenic dendritic cells and the quest for transplant tolerance. Nat Rev Immunol. 2007;7(8):610 21.

41. Bamboat ZM, Ocuin LM, Balachandran VP, Obaid H, Plitas G, DeMatteo RP. Conventional DCs reduce liver ischemia/reperfusion injury in mice via IL-10 secretion. J Clin Invest. 2010;120(2):55969.

42. Zhang M, Ueki S, Kimura S, Yoshida O, Castellaneta A, Ozaki KS, et al. Roles of dendritic cells in murine hepatic warm and liver transplantation-induced cold ischemia/reperfusion injury. Hepatology. 2013;57(4):1585-96.

43. Ozaki KS, Kimura S, Nalesnik MA, Sico RM, Zhang M, Ueki $\mathrm{S}$, et al. The loss of renal dendritic cells and activation of host adaptive immunity are long-term effects of ischemia/ reperfusion injury following syngeneic kidney transplantation. Kidney Int. 2012;81(10):1015-25.
44. Lanier LL. NK cell recognition. Annu Rev Immunol. 2005;23:22574.

45. Karre K, Ljunggren HG, Piontek G, Kiessling R. Selective rejection of H-2-deficient lymphoma variants suggests alternative immune defence strategy. Nature. 1986;319(6055):675-8.

46. Li XC. The significance of non-T-cell pathways in graft rejection: implications for transplant tolerance. Transplantation. 2010;90(10): 1043-7.

47. Yu G, Xu X, Vu MD, Kilpatrick ED, Li XC. NK cells promote transplant tolerance by killing donor antigen-presenting cells. J Exp Med. 2006;203(8):1851-8.

48. Kim HJ, Lee JS, Kim A, Koo S, Cha HJ, Han JA, et al. TLR2 signaling in tubular epithelial cells regulates NK cell recruitment in kidney ischemia-reperfusion injury. J Immunol. 2013;191(5):265764.

49. Kim HJ, Lee JS, Kim JD, Cha HJ, Kim A, Lee SK, et al. Reverse signaling through the costimulatory ligand $\mathrm{CD} 137 \mathrm{~L}$ in epithelial cells is essential for natural killer cell-mediated acute tissue inflammation. Proc Natl Acad Sci U S A. 2012;109(1):E13-22.

50. Feng M, Li G, Qian X, Fan Y, Huang X, Zhang F, et al. IL-17Aproducing NK cells were implicated in liver injury induced by ischemia and reperfusion. Int Immunopharmacol. 2012;13(2): $135-40$.

51. Zhang ZX, Wang S, Huang X, Min WP, Sun H, Liu W, et al. NK cells induce apoptosis in tubular epithelial cells and contribute to renal ischemia-reperfusion injury. J Immunol. 2008;181(11):7489 98.

52. Zhou W, Farrar CA, Abe K, Pratt JR, Marsh JE, Wang Y, et al. Predominant role for C5b-9 in renal ischemia/reperfusion injury. J Clin Invest. 2000;105(10):1363-71.

53. Ricklin D, Hajishengallis G, Yang K, Lambris JD. Complement: a key system for immune surveillance and homeostasis. Nat Immunol. 2010;11(9):785-97.

54. Farrar CA, Asgari E, Schwaeble WJ, Sacks SH. Which pathways trigger the role of complement in ischaemia/reperfusion injury? Front Immunol. 2012;3:341.

55. Peng Q, Li K, Smyth LA, Xing G, Wang N, Meader L, et al. C3a and $\mathrm{C} 5 \mathrm{a}$ promote renal ischemia-reperfusion injury. J Am Soc Nephrol. 2012;23(9):1474-85.

56. Moller-Kristensen M, Wang W, Ruseva M, Thiel S, Nielsen S, Takahashi K, et al. Mannan-binding lectin recognizes structures on ischaemic reperfused mouse kidneys and is implicated in tissue injury. Scand J Immunol. 2005;61(5):426-34.

57. de Vries B, Walter SJ, Peutz-Kootstra CJ, Wolfs TG, van Heurn LW, Buurman WA. The mannose-binding lectinpathway is involved in complement activation in the course of renal ischemia-reperfusion injury. Am $\mathrm{J}$ Pathol. 2004;165(5):1677-88.

58. Collard CD, Vakeva A, Morrissey MA, Agah A, Rollins SA, Reenstra WR, et al. Complement activation after oxidative stress: role of the lectin complement pathway. Am J Pathol. 2000;156(5): $1549-56$.

59. Schwaeble WJ, Lynch NJ, Clark JE, Marber M, Samani NJ, Ali $\mathrm{YM}$, et al. Targeting of mannan-binding lectin-associated serine protease- 2 confers protection from myocardial and gastrointestinal ischemia/reperfusion injury. Proc Natl Acad Sci U S A. 2011;108(18):7523-8.

60. van der Pol P, Schlagwein N, van Gijlswijk DJ, Berger SP, Roos A, Bajema IM, et al. Mannan-binding lectin mediates renal ischemia/ reperfusion injury independent of complement activation. Am J Transplant. 2012;12(4):877-87.

61. Engelmann B, Massberg S. Thrombosis as an intravascular effector of innate immunity. Nat Rev Immunol. 2013;13(1):34-45.

62. Giesen PL, Rauch U, Bohrmann B, Kling D, Roque M, Fallon JT, et al. Blood-borne tissue factor: another view of thrombosis. Proc Natl Acad Sci U S A. 1999;96(5):2311-5. This review gives a 
comprehensive overview of recent work on interactions of thrombosis and innate immunity.

63. Shrivastava S, McVey JH, Dorling A. The interface between coagulation and immunity. Am J Transplant. 2007;7(3):499-506.

64. Semeraro F, Ammollo CT, Morrissey JH, Dale GL, Friese P, Esmon NL, et al. Extracellular histones promote thrombin generation through platelet-dependent mechanisms: involvement of platelet TLR2 and TLR4. Blood. 2011;118(7):1952-61.

65. Duerschmied D, Suidan GL, Demers M, Herr N, Carbo C, Brill A, et al. Platelet serotonin promotes the recruitment of neutrophils to sites of acute inflammation in mice. Blood. 2013;121(6):1008-15.

66. Matsuyama M, Yoshimura R, Akioka K, Okamoto M, Ushigome $\mathrm{H}$, Kadotani Y, et al. Tissue factor antisense oligonucleotides prevent renal ischemia-reperfusion injury. Transplantation. 2003;76(5):786-91.

67. Sevastos J, Kennedy SE, Davis DR, Sam M, Peake PW, Charlesworth JA, et al. Tissue factor deficiency and PAR-1 deficiency are protective against renal ischemia reperfusion injury. Blood. 2007;109(2):577-83.

68. Loubele ST, Spek CA, Leenders P, van Oerle R, Aberson HL, Hamulyak K, et al. Activated protein $\mathrm{C}$ protects against myocardial ischemia/ reperfusion injury via inhibition of apoptosis and inflammation. Arterioscler Thromb Vasc Biol. 2009;29(7):1087-92.

69. Kayler LK, Srinivas TR, Schold JD. Influence of CIT-induced DGF on kidney transplant outcomes. Am J Transplant. 2011;11(12): 2657-64.

70. Mikhalski D, Wissing KM, Ghisdal L, Broeders N, Touly M, Hoang $\mathrm{AD}$, et al. Cold ischemia is a major determinant of acute rejection and renal graft survival in the modern era of immunosuppression. Transplantation. 2008;85(7 Suppl):S3-9.

71. Opelz G, Dohler B. Multicenter analysis of kidney preservation. Transplantation. 2007;83(3):247-53.

72. Goh CC, Ladouceur M, Peters L, Desmond C, Tchervenkov J, Baran D. Lengthy cold ischemia time is a modifiable risk factor associated with low glomerular filtration rates in expanded criteria donor kidney transplant recipients. Transplant Proc. 2009;41(8): 3290-2.

73. Kim SM, Ahn S, Min SI, Park D, Park T, Min SK, et al. Cold ischemic time is critical in outcomes of expanded criteria donor renal transplantation. Clin Transplant. 2013;27(1):132-9. Landmark study demonstrating the beneficial effects of machine perfusion.

74. Giessing M, Fuller TF, Friedersdorff F, Deger S, Wille A, Neumayer HH, et al. Outcomes of transplanting deceased-donor kidneys between elderly donors and recipients. J Am Soc Nephrol. 2009;20(1):37-40
75. Moers C, Pirenne J, Paul A, Ploeg RJ, Machine Preservation Trial Study Group. Machine perfusion or cold storage in deceased-donor kidney transplantation. N Engl J Med. 2012;366(8):770-1.

76. Moers C, Smits JM, Maathuis MH, Treckmann J, van Gelder F, Napieralski BP, et al. Machine perfusion or cold storage in deceased-donor kidney transplantation. N Engl J Med. 2009;360(1):7-19.

77. St Peter SD, Imber CJ, Friend PJ. Liver and kidney preservation by perfusion. Lancet. 2002;359(9306):604-13.

78. Tullius SG, Garcia-Cardena G. Organ procurement and perfusion before transplantation. N Engl J Med. 2009;360(1):78-80.

79. Patel H, Smith RA, Sacks SH, Zhou W. Therapeutic strategy with a membrane-localizing complement regulator to increase the number of usable donor organs after prolonged cold storage. J Am Soc Nephrol. 2006;17(4):1102-11.

80. Pratschke S, Bilzer M, Grutzner U, Angele M, Tufman A, Jauch $\mathrm{KW}$, et al. Tacrolimus preconditioning of rat liver allografts impacts glutathione homeostasis and early reperfusion injury. J Surg Res. 2012;176(1):309-16.

81. Ambros JT, Herrero-Fresneda I, Borau OG, Boira JM. Ischemic preconditioning in solid organ transplantation: from experimental to clinics. Transpl Int. 2007;20(3):219-29.

82. van den Akker EK, Manintveld OC, Hesselink DA, de Bruin RW, Ijzermans JN, Dor FJ. Protection against renal ischemia-reperfusion injury by ischemic postconditioning. Transplantation. 2013;95(11): 1299-305.

83. Kharbanda RK, Mortensen UM, White PA, Kristiansen SB, Schmidt MR, Hoschtitzky JA, et al. Transient limb ischemia induces remote ischemic preconditioning in vivo. Circulation. 2002;106(23):2881-3.

84. Selzner N, Boehnert M, Selzner M. Preconditioning, postconditioning, and remote conditioning in solid organ transplantation: basic mechanisms and translational applications. Transplant Rev (Orlando). 2012;26(2):115-24.

85. Reilly M, Miller RM, Thomson MH, Patris V, Ryle P, McLoughlin L, et al. Randomized, double-blind, placebo-controlled, doseescalating phase I, healthy subjects study of intravenous OPN305, a humanized anti-TLR2 antibody. Clin Pharmacol Ther. 2013;94(5):593-600.

86. Hutchinson JA, Riquelme P, Sawitzki B, Tomiuk S, Miqueu P, Zuhayra $\mathrm{M}$, et al. Cutting edge: immunological consequences and trafficking of human regulatory macrophages administered to renal transplant recipients. J Immunol. 2011;187(5):2072-8.

87. Geissler EK. The ONE study compares cell therapy products in organ transplantation: introduction to a review series on suppressive monocyte-derived cells. Transplant Res. 2012;1(1):11. doi:10. 1186/2047-1440-1-11. 